\title{
Is Clinical Scenario Simulation Teaching Effective in Cultivating the Competency of Nursing Students to Recognize and Assess the Risk of Pressure Ulcers?
}

\author{
Yan-Li Du' \\ Chun-Hua Ma' \\ Yu-Feng Liao' \\ Lu Wang ${ }^{2}$ \\ Ya Zhang' \\ Geng $\mathrm{Niu}^{3}$
}

'School of Medical Technology and Nursing, Shenzhen Polytechnic, Shenzhen, 518055, Guangdong, People's Republic of China; ${ }^{2}$ Delivery Center, Shenzhen Maternity \& Child Healthcare Hospital, Shenzhen, 518028, Guangdong, People's Republic of China; ${ }^{3}$ Shenzhen Elderly Healthcare College, Shenzhen Polytechnic, Shenzhen, Guangdong, 518055, People's Republic of China
Correspondence: Geng Niu Shenzhen Elderly Healthcare College, Shenzhen Polytechnic, Shenzhen, 5I8055, Guangdong, People's Republic of China

Tel +8675586379018

Fax +8675526731867

Email niugeng_dr@163.com
Objective: To evaluate the effectiveness of a clinical scenario simulation method among nursing students for assessing the risk of patients developing pressure ulcers compared with the traditional didactic method.

Methods: This experimental study was a controlled trial with single-blind assessments. Nursing students $(n=47)$ were randomly assigned to either a control or an experimental group. The control group $(\mathrm{n}=21)$ was instructed using traditional didactic methods that only delivered knowledge of pressure ulcers, while the experimental group $(n=26)$ received a clinical scenario simulation-based method for cultivating the competence to assess the risk of pressure ulcers. Participants underwent pre- and post-intervention based on the objective structured clinical examination (OSCE) comprising objective performance criteria. Data were analyzed using a $t$-test in the SPSS Statistics software program at a significance level of 0.05 .

Results: No significant differences were observed regarding age or the mean scores of the OSCE in pre-intervention between the two groups. Following the intervention, the mean score of the experimental group's performance was higher $(29.04 \pm 6.00)$ compared with the control group $(12.38 \pm 4.15)(P=0.000)$. There were statistical differences between the two groups. Nursing students in the clinical scenario simulation group performed significantly better in recognizing and assessing the risk of pressure ulcers.

Conclusion: This study demonstrates that a clinical scenario simulation approach is more effective than employing the traditional didactic method for cultivating students' assessment ability regarding pressure ulcers. This student-centered, clinical scenario simulation method can help to effectively develop students' competency in recognizing and assessing the risk of pressure ulcers, thereby providing a solid foundation for their clinical practice towards enhanced patient safety.

Keywords: pressure ulcer, clinical scenario simulation, didactic method, patient safety, competence, systematic assessment

\section{Introduction}

"Patient safety" refers to the absence of preventable harm being done to a patient during the process of delivering healthcare, ${ }^{1}$ and is currently recognized as a significant and growing global public health challenge. ${ }^{2}$ Available evidence indicates that approximately one in 10 patients are harmed while receiving hospital care in high-income countries. ${ }^{3}$ Annually, 134 million adverse events occur due to unsafe care in low and middle-income country hospitals. ${ }^{4}$ The lack of focus on 
patient safety has significant financial implications for all countries. Accordingly, in May 2019, the 72nd World Health Assembly endorsed the establishment of World Patient Safety Day to be observed annually on September 17, to raise global awareness about patient safety and encourage worldwide solidarity and action.

Unsafe factors such as medication errors, healthcareassociated infections, unsafe surgical care, and accidental injuries are prevailing avenues of patient harm. In China, pressure ulcers are a primary source of accidental injury. A pressure ulcer (recently renamed a "pressure injury") is a

localized injury to the skin and/or underlying tissue, usually over a bony prominence, as a result of pressure, or pressure in combination with shear stress and/or friction. $^{5}$

Pressure ulcers can cause significant patient harm including pain, infection, and extended hospital stays, ${ }^{6}$ as well as an increase in morbidity and mortality. ${ }^{7}$ Pressure ulcer incidences are widely considered as indicators for measuring the quality of healthcare provided. ${ }^{8,9}$ In Europe, the prevalence of pressure ulcers in hospitals ranges from $8.9 \%-18.2 \% .^{10-12}$

Prevention plays a vital role in the early identification of patients at risk of developing lesions. ${ }^{13}$ However, only $10.8-13.9 \%$ of patients at risk of developing pressure ulcers received adequate prevention care. Contrastingly, more than $70 \%$ of patients without such a risk received a form of prevention, signifying redundant and inefficient care processes. ${ }^{14,15}$ Lack of knowledge and a negative attitude toward pressure ulcer prevention have been identified as common barriers in clinical practice. ${ }^{16}$

Although the guidelines and best practices on pressure ulcer prevention are updated every five years and are easily accessible by healthcare staff, the incidence of pressure ulcers in hospitals remains high. ${ }^{6}$ Nursing students, who will assume critical roles in patient care and risk prevention, should be actively trained to adequately understand real clinical situations and learn within a real-world context to provide safe care in clinical scenarios through critical thinking.

Education on hospitalization hazards is an essential aspect of nursing student training programs. ${ }^{17}$ Nevertheless, students' education may not adequately prepare them to eliminate hazards that result in adverse events, such as pressure ulcers. ${ }^{17}$ Nursing students' knowledge of pressure ulcer prevention has been identified as inadequate, with $54 \%$ of nursing students failing to identify the presence of such ulcers. ${ }^{18}$

The teaching model of pressure ulcers is still based on traditional lecturing, the content of which comprises the definition, causes, risk factors, high-risk aspects, preventive measures, pathological stages, treatment, and nursing of pressure ulcers. These theoretical topics are incomplete and dispersed within learning materials, making it challenging for students to find the connections between their knowledge and skills and learning and practice. Students' learning is passive and has a larger focus on single aspects of knowledge through didactic teaching. The application and integration of such fragmented knowledge to clinical practice have been largely ignored. Typically, nursing students find themselves at a loss within their practice when coping with the problem of pressure ulcers. Accordingly, there exists a gap in terms of translating knowledge into effective clinical practice.

Historically, bridging such a gap through didactic teaching methods appears to have been ineffective. Recent studies indicate the highly promising approach of adopting clinical simulations to help nursing students develop safety and quality competencies. ${ }^{19}$ These simulations can reproduce the clinical environment, thereby helping students to experience real-world environments while supporting the transference of competencies gained in the simulated environment to actual patient care in hospitals. ${ }^{20}$ These simulations will help students to understand the importance of nursing interventions to patient outcomes by reflecting on nursing performance. $^{21,22}$ Studies have demonstrated that the simulation approach can strengthen the confidence, interest, and clinical skills of nursing students. ${ }^{23}$

Despite the novel nature of applying clinical scenario simulations for pressure ulcer training, its effectiveness, compared with traditional didactic delivery, remains unclear. The purpose of this study was to evaluate the effectiveness of clinical simulation compared with classroom lectures in terms of delivering the assessment skills required by nursing students for treating pressure ulcers.

\section{Methods}

\section{Design and Sample}

This study was conducted as a single and controlled trial with single-blind assessments. Second-year adult nursing students $(\mathrm{n}=54)$ who started their studies in September 2018 participated in the trial. These students, all of whom had the same prior learning experience, completed the required credit hours for gaining basic medical 
knowledge in topics such as anatomy, physiology, and pathology. In the control group, the traditional didactic method was carried out. In the experimental group, simulated clinical scenarios were developed to reflect different situations including patient admission, hospitalization, and disease deterioration; a standardized patient (SP) was included in the simulations to inspire students' critical thinking systematically through activities like brainstorming, group activities, and discussions. We recruited one experienced male social personnel member with no medical background from our school's practical teaching demonstration base as a "standardized patient". We then conducted systematic training related to the patient's clinical symptoms, morphological characteristics, and disease history. Next, we effected a simulated yet realistic scenario focused on a standardized pressure ulcer patient. The aim of this process was to help students gradually recognize a patient's skin problems, analyze the risk factors of pressure ulcers, use scales to identify the risks, and propose measures for prevention. The objective structured clinical examination (OSCE) was applied before and after the intervention by both groups.

The trial took place in December 2019. Random numbers were generated by a dedicated person using the SPSS Statistics software program. These numbers were randomly divided into two groups, according to the sample size of the experimental and control groups, at a ratio of approximately $1: 1 ; 54$ students were randomized into the control group $(n=26)$ and the experimental group $(n=28)$; however, only 47 attended the trial and the study's final OSCE review. There were 44 female and 3 male students, whose ages ranged from 17-27 years $(20.47 \pm 1.457)$. There were 21 participants in the control group and 26 in the experimental group. The participant flow is detailed in Figure 1.

\section{Interventions}

The students received either the traditional didactic method or clinical simulation teaching. There was two support staff in our research, ie, professional nursing trainers, who participated in the simulation of clinical situations and the preparation of simulated teaching materials. The conventional classroom teaching comprised a 90-minute lecture delivered by two experienced teachers on the definitions, leading causes, risk factors, preventative measures, stages, treatments, and nursing measures for pressure ulcers, based on the required textbooks. The clinical scenario simulation comprised a 90minute simulation class using the identified clinical scenarios, as well as SP demonstrations conducted by the same two teachers as in the control group. The detailed procedure of this process is shown in Table 1. The design of the clinical scenario simulation was based on the workflow of pressure ulcer prevention, ${ }^{6}$ new guidelines for the prevention and treatment of pressure ulcers, ${ }^{24}$ and the Pressure Ulcer Knowledge Assessment Tool (PUKAT 2.0), which demonstrated good psychometric properties and could be used and disseminated internationally to assess knowledge about pressure ulcer prevention in nursing education, research, and practice. ${ }^{10}$

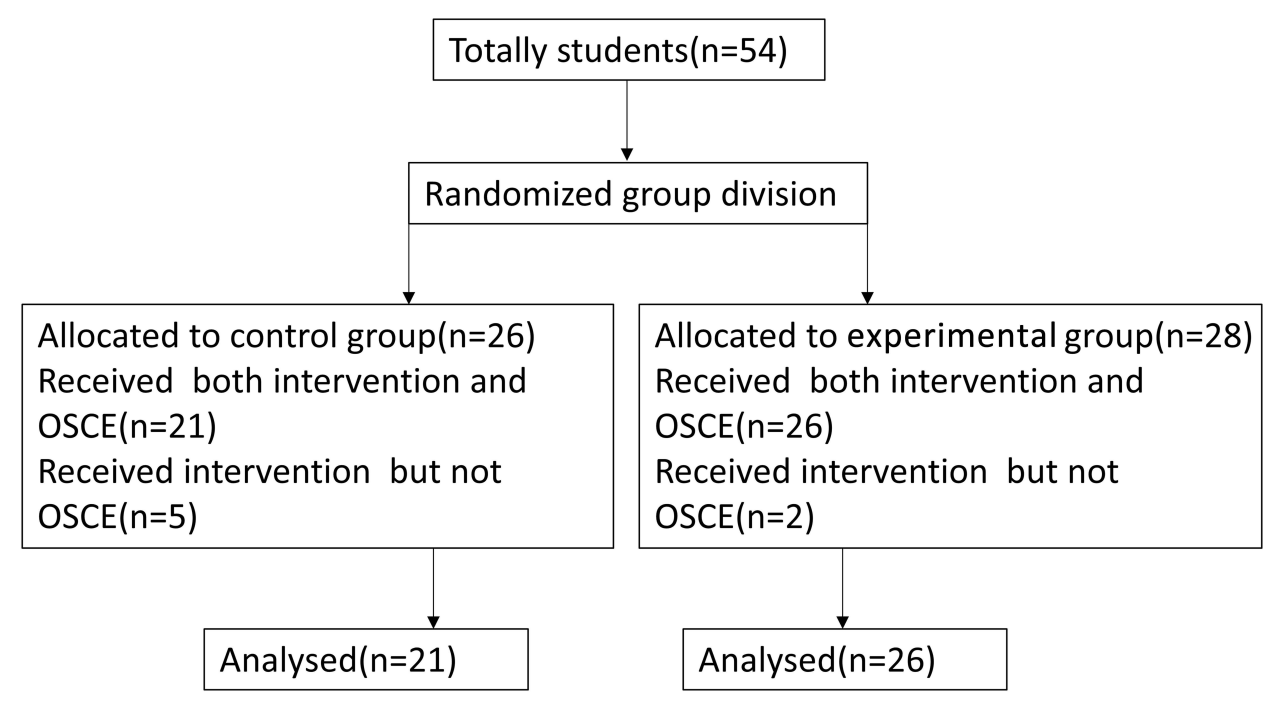

Figure I Participants flow diagram. 
Table I The Clinical Scenario-Simulation Procedure

\begin{tabular}{|c|c|c|c|c|}
\hline Part & Scenario & Aim & Description & $\begin{array}{c}\text { Tasks for Experimental } \\
\text { Students }\end{array}$ \\
\hline 1 & Introduction & $\begin{array}{l}\text { Pay much attention to keep } \\
\text { patient safety from pressure } \\
\text { ulcers. }\end{array}$ & $\begin{array}{l}\text { Case one. } \\
\text { - The elderly woman was admitted because her right femoral } \\
\text { neck was broken } 3 \text { months ago. } \\
\text { - She was forced to keep supine, keep silent, and seemed painful. } \\
\text { - When the nurse lifted her quilt, the stench hit. Her sacrococcygeal } \\
\text { region was rotten, with fecal impregnation at the rupture. }\end{array}$ & $\begin{array}{l}\text { - Divergent thinking and } \\
\text { brainstorm } \\
\text { - What happened to the patient? } \\
\text { - The harm to the patient? }\end{array}$ \\
\hline 2 & Admission & $\begin{array}{l}\text { Admission Assessment of } \\
\text { pressure ulcer }\end{array}$ & $\begin{array}{l}\text { Case two with a standard patient(SP). } \\
\text { - A } 75 \text {-year old man with the right femoral neck fracture. } \\
\text { - Lying in bed with a forced-supine. } \\
\text { - Rarely being turned over by caregiver. } \\
\text { - Ate little food by himself for several days. } \\
\text { - Before fracture: being healthy, good in spirits, had good sleep, } \\
\text { liked walking in the park. }\end{array}$ & $\begin{array}{l}\text { - Teamwork. } \\
\text { - Analyzed the high-risk factors } \\
\text { of pressure ulcers for him. } \\
\text { - Assessed the risk level by the } \\
\text { Braden Scale. }\end{array}$ \\
\hline 3 & Hospitalization & $\begin{array}{l}\text { Hospitalization reassessment of } \\
\text { pressure ulcer }\end{array}$ & $\begin{array}{l}\text { - During Hospitalization. } \\
\text { - Transient consciousness lost. } \\
\text { - Given electrocardiographic monitoring and gastric tube nasal } \\
\text { feeding } \\
\text { - Given laid left-side }\end{array}$ & $\begin{array}{l}\text { - Teamwork. } \\
\text { - Re-analyzed the high-risk } \\
\text { factors of pressure ulcers for } \\
\text { him. } \\
\text { - Reassessed the risk level by } \\
\text { Braden Scale. } \\
\text { - The time to reassessment }\end{array}$ \\
\hline 4 & Deteriorations & $\begin{array}{l}\text { Applicable prevention measures } \\
\text { for pressure ulcers. }\end{array}$ & $\begin{array}{l}\text { - Advanced deterioration of disease at 5th-day hospitalization with } \\
\text { - Fever } \\
\text { - Incontinence } \\
\text { - Catheter } \\
\text { - Electrocardiographic monitoring } \\
\text { - Gastric tube nasal feeding }\end{array}$ & $\begin{array}{l}\text { - Teamwork. } \\
\text { - Discussed and summarized the } \\
\text { measures of pressure ulcers. } \\
\text { - Applied them to SP. }\end{array}$ \\
\hline
\end{tabular}

Three typical clinical scenarios covering admission, hospitalization, and disease deterioration were designed (Table 1). We invited seven pressure-ulcer care experts to conduct a peer review of the goals, content, and tasks of the designed scenario simulation case. The experts agreed that the case designed for use in this study was reasonable and the content was effective. Each scenario was designed for pressure ulcer assessment or reassessment and was peer-reviewed internally to ensure content validity. These sessions occurred in a high-fidelity simulation room with the SP on a hospital bed during the process. Students were randomly arranged into six groups to complete the tasks of discovering, analyzing, and evaluating the SP's pressure ulcer risks.

\section{The Objective Structured Clinical Examination}

The OSCE is a method that can facilitate the assessment of practical skills and clinical competence among health professionals. ${ }^{25,26}$ Before conducting the teaching intervention, participants in the control and the experimental groups underwent a pre-test of the OSCE with the SP. Four days after the respective teaching interventions, the same OSCE was again used for the post-test. Based on PUKAT 2.0, the OSCE was designed to include three stations that focused on the students' ability to assess and prevent pressure ulcers (Table 2). The correct answer to each question was scored one point per item. For this study, the following were recorded: scenario 1: admission ( $5 \mathrm{~min}$ ); the total score was 13; scenario 2: hospitalization ( $5 \mathrm{~min}$ ); the total score was 13 ; scenario 3: deteriorations ( $5 \mathrm{~min}$ ); the total score was 13 . The total score of the OSCE as a whole was 39 points. Five members of the faculty measured the validity of the OSCE. The coefficient of variation index of the OSCE was (0.876), and the Cronbach's alpha coefficient was 0.809 , both of which were within the acceptable survey range. The researchers who examined both the OSCEs pre and postintervention were blinded to the participant groups. All examiners were associated with nursing faculty members within the college. The researchers who delivered both the control and experimental interventions were not involved in the OSCE data collection and analysis. 
Table 2 OSCE Procedure Scores

\begin{tabular}{|c|c|c|c|}
\hline OSCE & Description & \multicolumn{2}{|c|}{ Tasks for Students } \\
\hline \multirow{9}{*}{$\begin{array}{l}\text { Station I (13 } \\
\text { Scores, } 5 \mathrm{~min})\end{array}$} & \multirow{9}{*}{$\begin{array}{l}\text { Case three with standardized } \\
\text { patients } \\
\text { - A } 39 \text {-year old woman with } \\
\text { Multiple Organ Failure (MOF) } \\
\text { - Blood Pressure (BP): } 160 / \\
\text { I20mmHg } \\
\text { - Heart Rate(HR):I30/min } \\
\text { - Catheter } \\
\text {-Electrocardiographic monitoring } \\
\text { - Oxygen tube for oxygen } \\
\text { - Being supine } \\
\text { - Incontinence } \\
\text { - BMI=I5.8 }\end{array}$} & \multicolumn{2}{|l|}{ What would you do for the patient? } \\
\hline & & (I) Evaluation of skin & Score \\
\hline & & sacrococcygeal region & 1 \\
\hline & & heel & I \\
\hline & & the back side of the occipital & 1 \\
\hline & & elbow & I \\
\hline & & other parts & 1 \\
\hline & & \multicolumn{2}{|l|}{$\begin{array}{l}\text { (2)Pressure ulcers risk assessment } \\
\text { urinary catheter } \\
\text { oxygen tube } \\
\text { oxygen saturation sensor } \\
\text { passive position } \\
\text { fecal incontinence } \\
\text { BMI value } \\
\text { crumbs on the sheets }\end{array}$} \\
\hline & & $\begin{array}{l}\text { (3) Skin evaluation scores } \\
\text { Braden scale }\end{array}$ & 1 \\
\hline \multirow{10}{*}{$\begin{array}{l}\text { Station } 2 \text { (13 } \\
\text { Scores, } 5 \mathrm{~min})\end{array}$} & \multirow{10}{*}{$\begin{array}{l}\text { - On the } 2 n d \text { day during } \\
\text { hospitalization } \\
\text { - Coma } \\
\text { - Dyspnea } \\
\text { - Tracheotomy and using } \\
\text { a ventilator for } \\
\text { breathing. } \\
\text { - Other therapies were the same } \\
\text { as the above. }\end{array}$} & \multicolumn{2}{|c|}{ What would you provide for the patient in this condition? } \\
\hline & & (I) Evaluation of skin & Score \\
\hline & & auricular & I \\
\hline & & cheek & 1 \\
\hline & & acromion & 1 \\
\hline & & elbow & I \\
\hline & & hip & 1 \\
\hline & & $\begin{array}{l}\text { ankle latera } \\
\text { other parts }\end{array}$ & $\begin{array}{l}1 \\
1\end{array}$ \\
\hline & & $\begin{array}{l}\text { (2) Skin reassessment score } \\
\text { Braden scale }\end{array}$ & 1 \\
\hline & & $\begin{array}{l}\text { (3) New pressure ulcer risk assessment } \\
\text { coma } \\
\text { use of ventilator } \\
\text { oxygen saturation sensor } \\
\text { passive position } \\
\text { skin around the anus }\end{array}$ & $\begin{array}{l}\text { I } \\
\text { I } \\
\text { I } \\
\text { I } \\
\text { I }\end{array}$ \\
\hline
\end{tabular}

(Continued) 
Table 2 (Continued).

\begin{tabular}{|c|c|c|c|}
\hline OSCE & Description & Tasks for Students & \\
\hline \multirow{2}{*}{$\begin{array}{l}\text { Station } 3 \text { (13 } \\
\text { Scores, } 5 \mathrm{~min})\end{array}$} & \multirow{2}{*}{$\begin{array}{l}\text { - On the } 5 \text { th day } \\
\text { - Fever for about } 40^{\circ} \mathrm{C} \\
\text { - Ice packs were used on his head }\end{array}$} & \multicolumn{2}{|l|}{ Providing effective measures to prevent pressure ulcers } \\
\hline & & $\begin{array}{l}\text { Shorten turn over time }(\leq 2 \mathrm{~h}) \\
\text { Establish a turn over card } \\
\text { Skin assessment performed on each shift } \\
\text { Place warning signs at the head of the bed } \\
\text { Use air mattress } \\
\text { The bone protuberances protected with foam dressings } \\
\text { Change clothes whenever it get wet } \\
\text { Keep the skin clean and dry } \\
\text { Strengthen fecal incontinence nursing } \\
\text { Gastric tube and other tubes should be replaced regularly } \\
\text { Inform family members of the cause and harm of pressure ulcers } \\
\text { Pay attention to whether the head was frostbitten by cold compress or not } \\
\text { The Angle between the body and the bed surface in the lateral decubitus position } \\
\text { was less than } 30^{\circ} \text {, and the sacral tail was suspended }\end{array}$ & \\
\hline
\end{tabular}

Each simulation station comprised a high-fidelity simulation room and one female SP with a similar body shape lying on a hospital bed. Students were given three minutes to review the patient's medical records outside each station to prepare for the questions that would be asked and any measures they would need to effect. Five minutes were timed, beginning when they entered the simulation room. At each station, two evaluators rated students individually and calculated the total score of each student's OSCE.

\section{Ethical Considerations}

The study was conducted following the Declaration of Helsinki (as revised in 2013), and was approved by the Ethics Committee of the Shenzhen Elderly Healthcare College, China (No. 2019SZPOLYTECEC-016). Informed consent for inclusion in the study was obtained from participants in the two groups after briefing them about the aim and procedures of the research.

\section{Data Analysis}

The SPSS Statistics (v.19) (SPSS, Inc., Chicago, IL) software package was used to analyze and examine the data, based on descriptive and analytic statistics. An independent $t$-test was used to compare the mean age and scores of the OSCE before and after intervention between the two groups. Cronbach's alpha was set at 0.05 .

\section{Results}

As shown in Table 3, the average age of the experimental $(20.19 \pm 0.849)$ and control $(20.81 \pm 1.940)$ groups was not significantly different $(\mathrm{t}=-1.461, P=0.151)$

Table 3 Results of OSCE Post-Prevention

\begin{tabular}{|c|c|c|}
\hline & $\begin{array}{c}\text { Experimental } \\
\text { Group } \\
(n=26)\end{array}$ & $\begin{array}{l}\text { Control } \\
\text { Group } \\
(n=21)\end{array}$ \\
\hline Age & $20.19 \pm 0.849$ & $20.81 \pm 1.940$ \\
\hline $\mathrm{t}$ & \multicolumn{2}{|c|}{$-|.46|$} \\
\hline$P$ & \multicolumn{2}{|c|}{0.151} \\
\hline Scenario I:admission & $9.00 \pm 3.37$ & $4.38 \pm 1.63$ \\
\hline $\mathrm{t}$ & \multicolumn{2}{|c|}{5.753} \\
\hline$P$ & \multicolumn{2}{|c|}{$<0.001$} \\
\hline $\begin{array}{l}\text { Scenario 2: } \\
\text { hospitalization }\end{array}$ & $10.31 \pm 1.95$ & $4.33 \pm 2.18$ \\
\hline $\mathrm{t}$ & \multicolumn{2}{|c|}{9.910} \\
\hline$P$ & \multicolumn{2}{|c|}{$<0.001$} \\
\hline $\begin{array}{l}\text { Scenario3: } \\
\text { deteriorations }\end{array}$ & $9.73 \pm 3.12$ & $3.67 \pm 2.54$ \\
\hline $\mathrm{t}$ & \multicolumn{2}{|c|}{6.900} \\
\hline$P$ & \multicolumn{2}{|c|}{$<0.001$} \\
\hline OSCE Total & $29.04 \pm 6.00$ & $12.38 \pm 4.15$ \\
\hline $\mathrm{t}$ & \multicolumn{2}{|c|}{10.799} \\
\hline$P$ & \multicolumn{2}{|c|}{$<0.001$} \\
\hline
\end{tabular}


(Table 3). Both groups exhibited similar pre-intervention OSCE scores with no statistical differences. However, each station's mean OSCE score and the total postintervention score showed significant differences between the two groups. Two independent sample $t$-tests were performed between the experimental and control groups in scenarios 1, 2, and 3 and for the OSCE's total scores. The test results were all less than 0.001 and the difference was statistically significant. The scores were much higher in the experimental than in the control group.

\section{Discussion}

To improve the curriculum addressing pressure ulcers, in the present study, we shifted the traditional didactic teaching to using a clinical simulation by creating true-to-life clinical situations. These were represented by the inclusion of an SP to guide students through independent learning, analysis, and creating a summary for different patient situations, thereby encouraging them to apply the evaluated knowledge and skills to assess the risk of pressure ulcers in different conditions and to directly implement effective preventive measures for the SP. Finally, the results of the simulation and the traditional didactic teaching, examined using the OSCE, exhibited a significant difference.

\section{A Clinical Scenario Simulation Combined with the Standardized Patient Teaching Method Can Stimulate Students' Interest in Learning and Effectively Promote Skills Transfer}

In the experimental group, students had the opportunity to learn and practice clinical skills in simulated clinical scenarios with an SP. They stated, "It was a great experience," and, "It was like dealing with a real patient ... Through simulation teaching and training, I learned how to apply my knowledge and assessment skills to the SP." Simulated scenarios are commended as a form of learner-centered active learning strategy, in which the educator acts as a facilitator of learning. ${ }^{20}$ Students expressed that they were interested in these simulations and regarded the method as a form of interactive learning, and a powerful means for transferring skills. ${ }^{27}$

In addition to paying attention to the SP's disease and assessing his (in case two) or her (in OSCE) skin condition, we should also pay more attention to effective communication with him/her.

\section{The Importance of Keeping Patients Safe from Pressure Ulcers}

In the introduction scenario, an image of a stage IV pressure ulcer of an actual patient with detailed descriptions ("the nurse lifted her quilt, and the stench hit. Her sacrococcygeal region was rotten ..." ") was shown to the experimental group. This scenario had a strong impact. Through divergent thinking, students gained a deeper understanding of the injury caused by pressure ulcers. They noted, "I was so affected by the scenario that I couldn't forget that image," and, "pressure ulcers are ... terrible and should never happen to patients." This scenario made students in the experimental group pay significantly more attention to the need for protecting patients from unsafe conditions or incidents, such as pressure ulcers. As one student noted, "We must pay sufficient attention to the patient's skin to avoid pressure ulcers."

\section{Admission Assessment of Pressure Ulcers}

When a patient is admitted to the hospital, initial assessments including risk and skin assessment should be initiated to prevent the development of pressure ulcers. All patients should receive an initial evaluation using tools such as the Braden Scale. In this part of the simulation, the SP was admitted with a complex condition that included, eg, a "right femoral neck fracture, lying in bed in a forced-supine position, rarely being turned over by a caregiver, and eating little food." Under the guidance of teachers, students worked in small groups and employed self-studied models. Once they had completed the required tasks, they systematically summarized the high-risk factors and aspects related to the SP that could easily lead to them developing pressure ulcers. The students then learned how to use the Braden Scale to assess the risk of the SP developing pressure ulcers.

In practice, missing or delayed initial assessments upon hospital admission remains frequent due to pressure ulcers being a low priority task in actual care; this often results in the patient developing new pressure ulcers or the worsening of existing ulcers, particularly when the patient's overall status is severe. ${ }^{6}$ We emphasize that nursing students must learn to address a patient's primary disease processes, deliver the required care, and identify any potential risk of pressure ulcers developing, which may ultimately lead to an adverse event. 
To examine students' awareness of assessing the risk of pressure ulcers developing at the moment of admission, the SP in the first station of the OSCE presented as a critically ill patient experiencing multiple organ failure. The results showed that, while both groups took the necessary measures to care for the primary disease, the students in the experimental group $(9.00 \pm 3.37)$ paid more attention to the patient's skin assessment and were skilled at applying the Braden Scale to assess the risk of pressure ulcers compared with the control group (4.38 \pm 1.63). There were significant differences between the two groups in the scoring of this part $(P=0.000)$ (Table 3). This suggested that the simulated scenario helped to cultivate students' awareness of the need for preventing pressure ulcers as a process starting with a patient's admission. Students in the control group stated, "I was surprised that thepatient was lying in bed," and, "Faced with her serious illness, I only thought of providing [the] necessary nursing measures but I was completely unaware of any potential skin problems." Students in the experimental group responded,

In the admission scenario, we had to considerall the necessarysteps, including delivering nursing interventions for the patient's serious disease and assessing the risk of pressure ulcers.

\section{Hospitalization Reassessment of Pressure Ulcers}

A patient's condition may change during hospitalization. The best clinical practice recommends reassessing pressure ulcers in the case of a patient's condition worsening. Missing a reassessment may result in low awareness among nurses of preventing the development of pressure ulcers. ${ }^{6}$ Thus, in the hospitalization scenario, the SP (the same patient as above) acted in a manner that involved the following: "transient consciousness lost; given electrocardiographic monitoring and gastric-tube nasal feeding, and moved onto their left-side." All of these aspects were highrisk factors for developing pressure ulcers.

The teachers introduced the tasks involved in this part. Students in the experimental group analyzed the risk factors first and then reappraised the risk level for developing pressure ulcers using the Braden Scale. The risk level was higher than in the admission scenario noted above.

The hospitalization scenario for the second station of the OSCE was used to review whether students had gained reassessment awareness of pressure ulcers when the patient's condition changed. The results showed that students in the control group mainly provided nursing care that addressed changes in the patient's disease condition. They exhibited limited knowledge; eg, they were aware of the Braden Scale but lacked awareness of how to use it and the need for reassessing the risk of pressure ulcers. Students noted, "Having the right knowledge did not mean that you could effectively use it in practice," and, "we took little action regarding reassessment." The experimental group performed better than the control group in applying relevant knowledge and skills to reassess the patient's risk level $(P=0.000)$. Students in the experimental group noted, "A structured approach ... was presented in the simulatedclassroom."

\section{Applicable Prevention Measures for Pressure Ulcers}

Many practical strategies are in place to prevent pressure ulcers, such as repositioning the patient every two hours (at the maximum) or according to their specific condition. When a patient is lying in bed in a semi-Fowler's position, both the top of the bed and the area supporting the upper legs should be elevated at an angle of $30^{\circ}$. To increase students' skills in providing effective preventative measures, we set the third scenario to include the advanced deterioration of the SP's disease and included aspects such as fever and incontinence. The teachers presented many applicable preventative steps to the experimental group. The students discussed and summarized the measures in place for treating pressure ulcers and applied them to the SP.

At the third station of the OSCE, we aimed to check the students' practical abilities to provide preventative measures for the same SP as in the above stations. Students in the control group were able to describe selected preventive measures for avoiding the development of pressure ulcers but the actions were not targeted $(3.67 \pm 2.54)$. Moreover, they had difficulty applying their knowledge to patient care settings during the simulation. However, they learned systematic knowledge through the course content and were able to articulate the risks and preventative measures regarding pressure ulcers in their assignments and end-of-course exam. They noted, "I knew to change the patient's position every two hours theoretically," and, "We did not know how to translate and apply what we had learned in class." This indicated that there 
was a significant gap between having knowledge and its real-world application. ${ }^{28}$

Conversely, students in the experimental group reevaluated the risk of pressure ulcers using the Braden Scale. They carried out effective preventive measures for the SP for each high-risk factor $(9.73 \pm 3.12)$, thereby meeting the learning outcomes of the session. There was a statistical significance between the two groups $(P=$ 0.000). This indicated that if nursing students could not apply their knowledge and skills learned in the academic environment to clinical settings, teaching would have little value. These results implied that traditional lecturing in class may not be conducive in terms of knowledge and skills transfer into clinical practice.

The ability to transfer skills from one environment to another will be determined by a group's similarity and the environment. The authenticity of a mock environment may be detrimental to a student's ability to engage with a simulated learning experience and the transferability of what is learned through this process to a real-world clinical setting. ${ }^{29}$ To meet the above requirements, we intricately designed and replicated a clinical environment for different scenarios in the simulation class involving the SP and the OSCE.

The results of the OSCE for this part suggested that transferring students' newly acquired skills and knowledge to real-world clinical settings was more successful for the experimental group using the simulation approach compared with the control group who received lecturing only. This result was consistent with other research. ${ }^{30}$

\section{Limitations}

Although the results of this study showed that the students who used the clinical scenario simulation teaching method had higher performance scores compared with students who received the traditional teaching method, due to the limited total number of grade-two students included in this study, the survey had a small sample size. As such, the results of this study are somewhat biased. In the future, it is hoped that more students from other grades will be included in similar surveys and that more school students will be included in the survey to expand the sample size.

\section{Conclusion}

The findings of this study suggest that the clinical scenario simulation teaching method with an SP is valuable and effective for developing nursing students' competence when conducting a risk assessment for the development of pressure ulcers, which is critical for preventing accidental injury among patients. Accordingly, this teaching modality is expected to be applied to other nursing educational fields to cultivate nursing students' competence and enhancing patient safety and healthcare quality.

\section{Acknowledgments}

We thank Dr. Yang Gong of the School of Biomedical Informatics, the University of Texas Health Science Center at Houston for his critical reading and revise of this manuscript.

\section{Funding}

This study was funded by the Shenzhen Polytechnic Fund (7019310020J) and (6021310006K). The funding body had no role in the design of the study and collection, analysis, and interpretation of data and in writing the manuscript.

\section{Disclosure}

The authors declare that they have no competing interests.

\section{References}

1. World Health Organisation; 2019. Available from: https://www.who. int/patientsafety/en/. Accessed June 21, 2021.

2. Director-General. Patient safety Global action on patient safety; 2019. Available from: https://apps.who.int/iris/handle/10665/327526. Accessed June 21, 2021.

3. Fareed N, Mick SS. To make or buy patient safety solutions: a resource dependence and transaction cost economics perspective. Health Care Manage Rev. 2011;36(4):288-298. doi:10.1097/ HMR.0b013e318225998b

4. In crossing the global quality chasm: improving health care worldwide. Washington (DC); 2018.

5. Care A. Australian commission on safety and quality in health care. Safety Qual Improvement Guide Standard. 2010;8.

6. Wang J, Gong Y. Potential of decision support in preventing pressure ulcers in hospitals. Stud Health Technol Inform. 2017;241:15-20.

7. Sayan HE, Girgin NK, Asan A. Prevalence of pressure ulcers in hospitalized adult patients in Bursa, Turkey: a multicentre, point prevalence study. J Eval Clin Pract. 2020;26(6):1669-1676. doi:10.1111/ jep. 13354

8. Gunningberg L, Stotts NA. Tracking quality over time: what do pressure ulcer data show? Int J Qual Health Care. 2008;20 (4):246-253. doi:10.1093/intqhe/mzn009

9. Baharestani MM, Black JM, Carville K, et al. Dilemmas in measuring and using pressure ulcer prevalence and incidence: an international consensus. Int Wound J. 2009;6(2):97-104. doi:10.1111/j.1742481X.2009.00593.X

10. Manderlier B, Van Damme N, Vanderwee K, Verhaeghe S, Van Hecke A, Beeckman D. Development and psychometric validation of PUKAT 2.0, a knowledge assessment tool for pressure ulcer prevention. Int Wound J. 2017;14(6):1041-1051. doi:10.1111/ iwj. 12758

11. Briggs M, Collinson M, Wilson L, et al. The prevalence of pain at pressure areas and pressure ulcers in hospitalised patients. $B M C$ Nurs. 2013;12(1):19. doi:10.1186/1472-6955-12-19 
12. Bredesen IM, Bjøro K, Gunningberg L, Hofoss D. The prevalence, prevention and multilevel variance of pressure ulcers in Norwegian hospitals: a cross-sectional study. Int J Nurs Stud. 2015;52 (1):149-156. doi:10.1016/j.ijnurstu.2014.07.005

13. Shahin ES, Dassen T, Halfens RJ. Incidence, prevention and treatment of pressure ulcers in intensive care patients: a longitudinal study. Int $J$ Nurs Stud. 2009;46(4):413-421. doi:10.1016/j. ijnurstu.2008.02.011

14. Beeckman D, Defloor T, Schoonhoven L, Vanderwee K. Knowledge and attitudes of nurses on pressure ulcer prevention: a cross-sectional multicenter study in Belgian hospitals. Worldviews Evid Based Nurs. 2011;8(3):166-176. doi:10.1111/j.1741-6787.2011.00217.x

15. Vanderwee K, Defloor T, Beeckman D, et al. Assessing the adequacy of pressure ulcer prevention in hospitals: a nationwide prevalence survey. BMJ Qual Saf. 2011;20(3):260-267. doi:10.1136/bmjqs.20 10.043125

16. Npuap E. PPPIA. Prevention and treatment of pressure ulcers: clinical practice guideline, $2^{\text {nd; }}$ 2014. Available from: https://www.sogou.com/link?url= hedJjaC29108pHSRcwWO9ggYJeADOLsxhmOJbIn56Q1LxBkpsK08trU bwSa4Y1XHjQM2Z1XNKq7Aas1PBV8fIPPL4CIfEp9f.. Accessed June 21, 2021.

17. Clay AS, Chudgar SM, Turner KM, et al. How prepared are medical and nursing students to identify common hazards in the intensive care unit? Ann Am Thorac Soc. 2017;14(4):543-549. doi:10.1513/ AnnalsATS.201610-7730C

18. Simonetti V, Comparcini D, Flacco ME, Di Giovanni P, Cicolini G. Nursing students' knowledge and attitude on pressure ulcer prevention evidence-based guidelines: a multicenter cross-sectional study. Nurse Educ Today. 2015;35(4):573-579. doi:10.1016/j. nedt.2014.12.020

19. Moura ECC. Simulation for the development of clinical competence in risk assessment for pressure ulcer. Acta Paul Enferm. 2013;26 (4):369-375. doi:10.1590/S0103-21002013000400011

20. Jeffries PR. A framework for designing, implementing, and evaluating simulations used as teaching strategies in nursing. Nurs Educ Perspect. 2005;26(2):96-103.

21. Weaver A. High-fidelity patient simulation in nursing education: an integrative review. Nurs Educ Perspect. 2011;32(1):37-40. doi: $10.5480 / 1536-5026-32.1 .37$
22. Lewis DY, Ciak AD. The impact of a simulation lab experiencefor nursing students. Nurs Educ Perspect. 2011;32(4):256-258. doi:10.5480/1536-5026-32.4.256

23. Cooper S, Beauchamp A, Bogossian F, et al. Managing patient deterioration: a protocol for enhancing undergraduate nursing students' competence through web-based simulation and feedback techniques. BMC Nurs. 2012;11(1):18. doi:10.1186/1472-6955-11-18

24. Epuap N. PPPIA. revention and Treatment of Pressure Ulcers/ Injuries: quick reference guide 2019; 2019. Available from: http:// www.internationalguideline.com/static/pdfs/Quick_Reference_ Guide-10Mar2019.pdf. Accessed June 21, 2021.

25. Bußenius L, Harendza S. Are different medical school admission tests associated with the outcomes of a simulation-based OSCE? BMC Med Educ. 2021;21(1):263-268. doi:10.1186/s12909-02102703-x

26. Lee $\mathrm{KC}$, Ho $\mathrm{CH}, \mathrm{Yu} \mathrm{CC}$, et al. The development of a six-station OSCE for evaluating the clinical competency of the student nurses before graduation: a validity and reliability analysis. Nurse Educ Today. 2020;84:104247-104252. doi:10.1016/j.nedt.2019.104247

27. Zarifsanaiey N, Amini M, Saadat F. A comparison of educational strategies for the acquisition of nursing student's performance and critical thinking: simulation-based training vs. integrated training (simulation and critical thinking strategies). BMC Med Educ. 2016;16(1):294. doi:10.1186/s12909-016-0812-0

28. Larew C, Lessans S, Spunt D, Foster D, Covington BG. Innovations in clinical simulation: application of Benner's theory in an interactive patient care simulation. Nurs Educ Perspect. 2006;27(1):16-21.

29. Ricketts B. The role of simulation for learning within pre-registration nursing education - a literature review. Nurse Educ Today. 2011;31 (7):650-654. doi:10.1016/j.nedt.2010.10.029

30. Kory PD, Eisen LA, Adachi M, Ribaudo VA, Rosenthal ME, Mayo PH. Initial airway management skills of senior residents: simulation training compared with traditional training. Chest. 2007;132(6):1927-1931. doi:10.1378/chest.07-1554
Risk Management and Healthcare Policy

\section{Publish your work in this journal}

Risk Management and Healthcare Policy is an international, peerreviewed, open access journal focusing on all aspects of public health, policy, and preventative measures to promote good health and improve morbidity and mortality in the population. The journal welcomes submitted papers covering original research, basic science, clinical \& epidemiological studies, reviews and evaluations, guidelines, expert opinion and commentary, case reports and extended reports. The manuscript management system is completely online and includes a very quick and fair peer-review system, which is all easy to use. Visit http://www.dovepress.com/testimonials.php to read real quotes from published authors. 